\title{
The impact of burnout toward affective commitment and turnover intention
}

\author{
Daffa Mahmod Rashad, Reni Rosari
}

Faculty of Economics and Business, Universitas Gadjah Mada, Yogyakarta, Indonesia

*Corresponding author: rrosari@ugm.ac.id

\begin{abstract}
This study aims to examine the influence of burnout components which consist of exhaustion, cynicism and reduced professional efficacy toward affective commitment and turnover intention on the study of supporting division employees in PT. XYZ. This research uses quantitative research design with survey method and use questionnaire as research instrument. Multiple linear regression method is used to test the hypothesis in this research. The results show that although the burnout components of cynicism and reduced professional efficacy have significant and negative effect on affective commitment, the exhaustion component has no effect on affective commitment. The results also proved that exhaustion, cynicism and reduced professional efficacy have significant and positive effect on turnover intention.
\end{abstract}

Keywords: burnout; exhaustion; cynicism; reduced professional efficacy, affective commitment, turnover intention JEL Classification Code: M12

DOI: 10.20885/jsb.vol24.iss1.art2

\section{Introduction}

In rapid change and development of today's business environment, organizations are encouraged to meet certain demands of the worlds' business competitions. All companies must respond to changing markets, technical advances and customer demands if they are willing to survive within competitions (Chen \& Yu, 2014). Those competitions stimulate organizations to improve their capabilities in order to successfully contend in the industry.

One of the major effects of the business competitions for an organization is the competition among employees. As unavoidable part of the people's work lives, some studies suggest that employees' competition can motivate employees to put more effort in achieving the results (Steinhage et al., 2017). However, on the other side, Hedges (2017) suggests that too much competition could be deadly for employees by killing morale, causing stress, and fostering backstabbing. According to a survey of the American Psychological Association, money, workplace and family responsibilities are the three major sources of stress among US adults. Stress is the manifestation of burnout in the organization. In the last decade, several studies have found substation of professional stress syndrome of burnout worldwide especially in western and developing countries (Maslach et al., 2001). In western countries, some studies found that occupational burnout has a possibility to predict work inability in initially healthy employees (Carod-Artal and Vazquez-Cabrera, 2013). Morgan (2017) found that unfair compensation is the top contributors to burnout for employees. In addition, in large companies, $15 \%$ of organizations with 2,500 or more employees blame burnout for over $50 \%$ of their annual turnover (Gouthro, 2017).

Within the last few years, several studies have focused on burnout syndrome in Asian and Chinese context (Carod-Artal and Vazquez-Cabrera, 2013). Study by Jung and Kim (2012) and Jung et al. (2012) in South Korea have reported that South Korean journalists and culinary hotel employees in Seoul experience high level of burnout from their work. Moreover, Lim et al. (2010) revealed that Singaporean nurses encounter high level of stress related to work. Similar finding in Saudi Arabia concludes that the commonness of burnout syndrome among multinational nurses appears to be high (Al-Turki et al., 2010). Hence, many countries have to bare the fact that the quality of work issue is global phenomenon which could not be avoided in this modern era. Various people especially worker 
in developing countries have to deal with the increased levels of work-related stress (Carod-Artal and Vazquez-Cabrera, 2013). Moreover, burnout and job-stress prevention strategy might not be common in those developing countries (Houtman et al., 2007).

Indonesia which is categorized as developing country might has similar situation with its worker. Almost all companies could not elude from change in their business operation in order to adapt with the changing business environment, including PT. XYZ as one of the biggest stated owned company in Indonesia. PT. XYZ is a subsidiary of an oil and gas company which manages and supervises the operational areas of upstream oil and gas work of its parent company as well as each of its subsidiaries with partnership scheme. PT. XYZ always try to provide their best performance which is reflected through its employees' performance. In 2016, PT. XYZ has been restructuring their company's structure particularly on supporting or enabler function divisions. PT. XYZ initiated to change the company's structure in order to implement Shared Service Organization (SSO) within the company. The purpose is to achieve more efficient business process, reduce the cost of the business operation and enhance operational excellence.

Usually, restructuring process of an organization results in an increase of workload especially in employees' daily routine tasks. According to American Psychological Association survey (2017), employees who are affected by change at work are more likely to experience chronic work stress, feel cynical and negative attitude toward others, more likely to distrust their employer and in turn plan to leave the organization within the next year. That phenomenon is closely related with burnout syndrome. High level of burnout rate is well documented in front-line professional staff, not only in human service institutions but also in a broader set of jobs outside human services (Maslach \& Jackson, 1981; Leiter \& Schaufeli, 1996). Thus, it might be implied that employees in PT. XYZ are experiencing burnout due to the escalation of stressors (Greenglass and Burke, 2002).

Burnout is a very complex phenomenon. There was no standard definition of burnout universally; different people interpret the term burnout as different things in different situations (Maslach et al., 2001). Maslach et al. (1996) as cited in Farradinna \& Halim (2016) defines staff burnout as "a condition of emotional exhaustion, depersonalization, and reduced personal accomplishment that can occur among individuals who work with people in some capacity". Earlier, Maslach and Jackson (1981) initially claimed that job burnout occurs in human service positions. Thus, it is implied that the definition and the characteristics of the three components of burnout apply when job burnout occurs in human service positions such as nurses, physicians, teachers, social workers, police officers and psychiatrists (Maslach \& Jackson, 1981).

Because of the concepts of burnout are expanded not only in human service professions but also into broader set of jobs. Schaufeli et al. (1996) as cited in Kim (2015) developed a general survey version of burnout in occupational groups outside human services profession (Jung and Kim, 2012; Atmaja, 2018). He addresses three job dimensions of exhaustion, cynicism and reduced professional efficacy which reflect the dimensions of emotional exhaustion, depersonalization and reduced personal accomplishment, respectively. In extending the definition, Maslach and colleagues (Masclach et al., 2001) interpret burnout as a prolonged response to chronic emotional interpersonal stressors on the job, and is defined by the three components of exhaustion, cynicism and reduced professional efficacy. There are slightly adjustments for the characteristics of its components compared with original components. These constructs more focuses on the employees' perception toward their job rather than the people involved in performing the job.

Thus, this research will adopt the concept of burnout that has been developed by Iwanicki and Schwab (1981) in more general occupations, in this context, the office worker. The emergence of three symptoms of burnout which are exhaustion, cynicism and reduced professional efficacy signify the existence of burnout among the employees. Leiter and Schaufeli (1996), here, state that exhaustion depicts work fatigue, cynicism examines indifference or a negative attitude toward one's general work and reduced professional efficacy portrays employee's negative expectation of his or her own work. 
Hereinafter, burnout has various negative effects in the workplace, not merely individuals who suffer from the burnout phenomenon. Burnout harms the human-being and affects the job, team and organization (Valcour, 2017). Protracted exposure to stressors such as overload works and lack of resources could trigger work-related stress; further, those unceasing accumulation of stress contributes to job burnout (Maslach et al., 1996, as cited in Maslach et al., 2001) Based on the data from Lynne (2017) both staff and employers acknowledge that burnout from overworked is a key cause in poor productivity, in turn, lead to more inclination to quit their job for other opportunities (Schawbel, 2017). Burnout and its components have proved to have effect on job performance, organizational commitment, turnover intention, and job satisfaction (Fogarty \& Kalbers, 2015; Shepherd et al., 2010; Cannon \& Herda, 2016; Nagar, 2012, Jung \& Kim 2012).

In this intense competition among the organizations, the importance of employees' commitment to the organization cannot be ignored. As described by Mowday et al., (1979) organizational commitment is a person's willingness to invest efforts to contribute to the organization to which he or she belongs. The existence of burnout could affect employees' commitment toward their organization. The evidence from entrepreneurial context and junior accountant postulates that as the level of burnout increases, the level of organizational commitment, and job satisfaction appear to be lower (Shepherd et al., 2010; Chong and Monroe, 2015; Brown \& Peterson, 1993). Thus, the absence of organizational commitment which is caused by burnout could jeopardize the organization performance in the long term.

However, Allen and Meyer (1990) developed the components of organizational commitment into: affective, continuance and normative commitment which reflect the extent to which employees want, need, and ought to do so, respectively. Affective commitment itself refers to employees' emotional attachment to, identification with, and involvement in, the organization (Allen and Meyer, 1990). From the definition, affective commitment is considered to have more emotional involvement than two other components. Moreover, the measurement of affective commitment is more reliable and is also the most important explanatory variable (Buys \& Rothmann, 2010). Affective commitment consistently explains more variance in outcome variables than the other two components (Allen \& Meyer, 1996). Besides, Meyer and Allen (1987) pointed out that the strongest evidence of affective commitment has been found in work experiences by employee. Therefore, this study will focus on affective commitment since the reason that burnout is mainly induced by over workload and frustrating working environment (Maslach et al., 2001; Schaufeli et al., 2009).

Like organizational commitment, negative effects of burnout influence affective commitment as well. Study by Fogarty and Kalbers (2015) confirm that burnout tendencies of depersonalization and reduced personal achievement are negatively influenced affective commitment of internal auditors. In addition, experienced burnout dimension of cynicism depicts lower affective commitment (Buys \& Rothmann, 2010). Evidently, burnout components of exhaustion, cynicism and reduced professional efficacy have been proved to predict negative influence on affective commitment (Jung \& Kim, 2012; Armstrong et al., 2015). Employees whose feeling high burnout rate will complain that they are tired for working, hate their jobs, and feel that they do not capable and suitable in that position which build the ignorance to involve in company's activities.

On the other hand, burnout not only has attitudinal consequences such as commitment and satisfaction, but also the behavioral consequences such as turnover, absenteeism (Cordes \& Dougherty, 1993; Jung \& Kim, 2012). Employees who experience emotional drained from their work report higher intention to leave their organization (Utami \& Nahartyo, 2013; Cho et al., 2017). Three burnout components of exhaustion, cynicism and reduced professional efficacy have also been proved to increase the employees' possibility to leave the organization (Huang et al., 2003). Thus, the condition of perpetual exposure to stress drives employees to experience work fatigue, bad perception towards their job, and low expectation of their competency to complete the job in accordance with the intended results. Thus, the condition of the increasing level of burnout will intensify the chance for employees leaving their organization (Jung et al., 2012; Kang et al., 2010). 
Therefore, based on the explanation above, this research will replicate the partial model proposed by Jung and Kim (2012). They have found that Journalists in Korea experience high level of burnout. In addition, burnout components of exhaustion, cynicism and reduced professional efficacy have significant and positive effect on turnover intention. However, affective commitment is only significantly influenced by cynicism and reduced professional efficacy. The difference of nationality and job context will become main consideration for the researcher to re-examine the concept. Previously, Jung and Kim (2012) use Korean newspaper journalist as their subject of analysis. Meanwhile, this research will adopt more general occupation particularly office workers on supporting divisions in PT. XYZ as the subject of analysis in order to re-examine whether the burnout components of exhaustion, cynicism and reduced professional efficacy influence affective commitment and turnover intention in different job contexts, different countries and nationalities.

\section{Literature Review}

\section{Burnout}

The term burnout was firstly introduced in the early 1970s by Freudenberger (1974) as a state of fatigue or frustration that resulted from professional relationships that failed to produce the expected rewards. At the near time, Maslach et al. (2001), a social psychology researcher, found that burnout began with the result of work conducted on emotion, arousal and the way in which people cope with emotion and manage their arousal (Maslach \& Jackson, 1981). Burnout is a negative psychological response to stress and has several characteristics in it such as emotional fatigue, reduced ability to complete tasks, and the occurrence of depersonalization (Cordes and Dougherty, 1993. Those characteristics are closely related to the universally accepted and comprehensive definition by Maslach and Jackson (1981) who define burnout as psychological syndrome of emotional exhaustion, depersonalisation and reduced personal accomplishment that can occur among individuals who work with other people in some capacity.

Initially, according to Maslach and Jackson (1981), burnout only found occurred in humanrelated occupation which consists of three components which have different meanings. Emotional exhaustion is characterized by a lack of energy and a feeling of used up emotional resources. Another component, depersonalization is marked by the development of indifference attitude and feelings toward people or client. Besides, the diminished personal accomplishment is indicated by the tendency to evaluate oneself negatively.

Schaufeli et al. (1996), as cited in Werang et al. (2015) developed more appropriate components in more general version including exhaustion, cynicism and reduced professional efficacy due to the increasing interests of burnout within not clearly people-oriented or non-human service positions such as office worker (Maslach et al., 2001). According to Leiter and Schaufeli (1996), exhaustion component addresses the work fatigue including both emotional and physical fatigue but do not make people as direct reference of those feelings. Cynicism depicts indifference or negative attitudes toward one's work in general rather than toward people. Finally, reduced professional efficacy assesses the individual's expectations of continued ineffectiveness at work.

\section{Affective Commitment}

The study of affective commitment has become the interesting variable studied in the last three decades. Most research has focused on emotional attachment to an organization and belief in it values as the "gold standard" for employee commitment (Solinger et al., 2008). Allen and Meyer (1990) stated that affective commitment is the emotional attachment to the organization, such that the strongly committed individual identifies with, is involved in, and enjoys membership of the organization. The emotionally committed employees remain in the organization because they want to.

Affective commitment is one of three components of organizational commitment besides continuance and normative commitment which represent the need and obligation to remain in the 
organization, respectively (Allen \& Meyer, 1996; Memari et al., 2013). Because the components are viewed as distinguishable part, employees could experience each of these psychological states to varying degrees (Allen \& Meyer, 1990). Some employees could feel a strong desire to remain in the organization but neither need nor oblige to do; in some cases, employees might feel that they have an obligation to stay but actually the do not want and so on. As there are conceptual differences among each organizational commitment components, Allen and Meyer (1990) suggest that each of the components have its own antecedents. By this reason, affective commitment is treated as an individual construct in this study.

\section{Turnover Intention}

Turnover intention is a predictor of an employee's propensity to look for other occupations signalling the intention to quit the current job (Jung et al., 2012). Research by Steel (2002) has proved that employees' turnover intention is the best predictor of actual turnover. Moreover, turnover intention is the subjective estimation of an individual in regards with the possibility for leaving an organization in the near future (Mowday et al., 1982, as cited in Jung et al., 2012). In general, turnover intention is defined as the likelihood of an employee leaving an organization (Grandey, 2000). On another term, Carmeli and Weisberg (2006) suggest that turnover intention is a withdrawal cognition process which consists of three stages: thinking about leaving an organization, finding another vocation, and finally having turnover intent with simple definition of intention to quit (O'Reilly, Chatman \& Caldwell, 1991; Cho et al, 2009).

\section{Burnout and Affective Commitment}

Several researches have examined the impact of burnout tendencies on affective commitment. Initially Tan and Akhtar (1998) in his study on Hong Kong banking organization postulated that affective commitment has an impact on burnout level. Tourigny et al. (2013) in their study on nurses and doctors in China revealed that emotional exhaustion is negatively related to affective commitment. The more emotional drains and work fatigues experienced by employees, reflecting low tendency of employees to be emotionally attached in remaining in the organization. In addition, in the field of Information System Professional, exhaustion was proved to have negative relationship with affective commitment (Armstrong et al., 2015; Enzmann et al., 1998). Thus, the exhaustion experienced by employees which is derived from their work will generate the feeling of dissociation to their organization.

For second component of burnout, Buys and Rothmann (2010) use term low mental distance which elaborated as depersonalization and cynicism. In their study on reformed church ministers in South Africa found that low mental distance has negative correlation with affective commitment. Thereto, Fogarty and Kalbers (2015) strengthen the previous study by finding that depersonalization is negatively correlated with affective organizational commitment. The higher the tendency to develop negative attitude and feelings toward people is followed by the lower involvement and attachment of employees to remain in the organization. The increased employees' feeling that they are doing improper work will lead employees to induce feelings of self-isolation from the organization.

Last but not least, reduced personal achievement is proved to be negatively related with affective commitment (Fogarty and Kalbers, 2015). The inclination to evaluate one's self negatively will impact on lower affective commitment of employees to the organization. The internal auditors in U.S organization tend to have lower affective commitment if they experience reduced personal achievement. Moreover, South Korean journalists were proved to experience higher level of burnout due to the increasing rate of reduced professional efficacy in doing their work (Jung \& Kim, 2012). The incapability in doing their job and lack of competency to achieve the desired outcomes make them become apathetic employees who generate the nature of indifference toward the organization resulting in their low involvement on organizational activities. 
Therefore, in line with the theory, argument and concept above, the author develops the following hypothesis:

H1a: Higher levels of exhaustion will predict lower levels of affective commitment.

H1b: Higher levels of cynicism will predict lower levels of affective commitment.

H1c: Higher levels of reduced professional efficacy will predict lower levels of affective commitment.

\section{Burnout and Turnover Intention}

Many studies have conducted the research to examine the effect of burnout on turnover intention. Burnout found to be uniquely contribute to the prediction of turnover intention (Plooy et al., 2010). A study by Cannon and Herda (2016) in auditors found that burnout is positively related to turnover intention; supporting the previous research of Herda and Lavelle (2012). In addition, from the evidence of South African Information and communication technologies (ICT) company proved that three dimensions of emotional exhaustion, depersonalisation and diminished personal accomplishment have positive and significant relationship with turnover intention (Plooy et al., 2010).

The increasing phenomenon of burnout syndrome in non human services occupation has been proved to have an effect on turnover intention as well. Jung et al., (2012) found that burnout dimensions of exhaustion, cynicism and non accomplishment had significant positive effects on turnover intention. If employees' burnout experienced increased, so did their chances of leaving the company (Kang et al., 2010; Freudenberger, 1975). Evidence from Journalism field by Reinardy (2011) supports that journalists who express their intention to leave the profession has significantly higher rates of exhaustion, cynicism and lower rates of professional efficacy.

One component of emotional exhaustion is considered to be the most important dimensions of burnout syndrome (Roelofs et al., 2005) and is proved to have significant positive impact on turnover intention (Tourigny et al., 2013; Chen \& Yu, 2014). Study on Internal Auditor reveals that emotional exhaustion is positively related to external turnover (Fogarty and Kalbers, 2015). Moreover, Cho et al. (2017) in the study of retail worker reveals that when emotional exhaustion increase, the propensity to leave also increase. Another study from Civil Servant report that higher level of exhaustion will induce greater intention to leave organization (Huang et al., 2003). The fatigue felt by employees which caused by their work will make them to feel unbearable with their job. Eventually, it will lead employees to trigger their desire to leave their organization and looking for a new job.

As a second component, cynicism is found to be positively related to turnover intention (Jung et al., 2012; Chen \& Yu, 2014). Plooy et al. (2010) proved that depersonalization has positive and significant relationship with turnover intention. In addition, Huang et al (2003) civil servants who experience higher level of cynicism have greater intention to quit jobs. The establishment of negative depiction regarding the work or people strongly induce individuals to quit their jobs. A negative attitude that they feel about their work will make employees think that their current job is not appropriate job for them. It will create a feeling of discomfort toward their work that will result in a desire to get out of the organization to find more appropriate job.

Fogarty and Kalbers (2015) found that as element of burnout, reduced personal accomplishment is significantly related to turnover intention. In sample of internal auditors, a feeling of evaluate oneself negatively bring up auditors to change for new job outside the organization. Besides, lower individual expectations toward their job contribution to the firm's outcome, the higher their inclination to leave the firm (Reinardy, 2011). The mismatch between employees' competences and the characteristics of the given job generates the feelings of employee's inability to perform the assigned task and to achieve the specified target. Thus, it causes the employee to quit their organization to find another more appropriate job rather than the job that they are currently working.

Thus, based on the theoretical concept and empirical evidence above, the authors hypothesized:

H2a: Higher levels of exhaustion will predict greater intentions to leave an organization. 
H2b: Higher levels of cynicism will predict greater intentions to leave an organization.

H2c: Higher levels of reduced professional efficacy will predict greater intentions to leave an organization.

Based on the elaboration of theoretical relationship that has been previously presented, it provides the basis and direction leading to the construction of model analysis, as follows.

Burnout

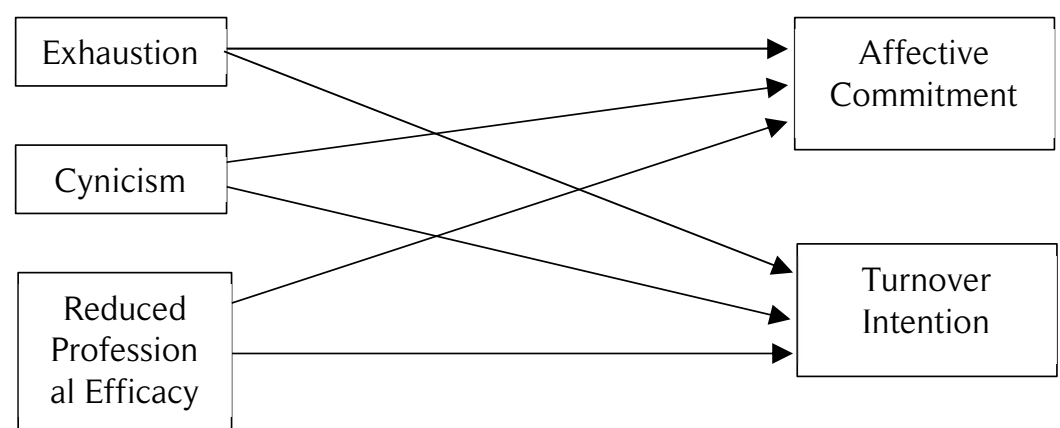

Figure 1. Research Model

\section{Methods}

\section{Subjects}

The subjects consisted of permanent employees from Oil \& Gas stated-owned company in Indonesia particularly those who are working in enabler functions or supporting divisions for minimum one year. These divisions included legal, relations, controller, commercial, internal audit, finance and treasury, supply chain management, human resources and general affairs, project portfolio and risk management, quality health safety security environment (QHSSE), information and communication technology and data management. Researcher contacted a human resource representative from the company and obtained permission to conduct surveys in January 2018. The general secretary distributed the questionnaires to the employees and then collected the completed questionnaires and returned them to researchers. A total of 110 questionnaires were distributed, and 99 were returned (response rate of $90 \%$ ) but only 94 questionnaires are eligible for further processing.

\section{Measurement}

\section{Burnout}

Burnout refers to psychological syndrome of emotional exhaustion, depersonalisation and reduced personal accomplishment that can occur frequently among individuals who work with other people in some capacity (Maslach, 1981). Due to this research focus job burnout in non-human services positions, the researcher adopts the Leiter and Schaufeli (1996) literature. They developed burnout's components in non-human services occupation as: exhaustion, cynicism, and reduced professional efficacy. Those components are measured by Maslach Burnout Inventory - General Survey instrument which is developed by Leiter \& Schaufeli (1996).

\section{Exhaustion}

Exhaustion component addresses the emotional and physical fatigue experienced by employees which derived from their work (Leiter \& Schaufeli, 1996). The sample exhaustion item includes "I feel emotionally drained from my work". 


\section{Cynicism}

Employee's distant attitudes toward their work in general rather than toward people (Leiter \& Schaufeli, 1996). The sample cynicism item includes "I have become less interested in my work since I started this job".

\section{Reduced professional efficacy}

Individual's negative expectations of continued effectiveness at work (Leiter \& Schaufeli, 1996). The sample reduced professional efficacy item includes "I can effectively solve the problems that arise in my work".

\section{Affective Commitment}

Meyer and Allen (1991) define affective commitment as an emotional attachment, identification, and involvement in the organization. Eight items Affective Organizational commitment scale by Allen and Meyer (1990) is used to measure the construct. The sample item is "I would be very happy to spend the rest of my career with this organization", and the question such "I do not feel a strong sense of belonging to my organization" will be reversed coded in the process.

\section{Turnover Intention}

Turnover intention is the subjective estimation of an individual regarding with the possibility for leaving an organization in the near future (Mowday et al., 1982, as cited in Jung et al., 2012). The instrument used to measure the turnover intention is adopted from three items of O'Reilly, Chatman and Caldwell (1991). The sample of turnover intention includes "I would prefer another mode ideal job than the one I now work in".

\section{Validity \& reliability testing}

Researcher use content validity as the validity testing method which make questionnaire items used in this research are already evaluated by other researchers within the same concept of study (Sekaran and Bougie, 2016). For the reliability test result, exhaustion, cynicism, reduced professional efficacy, affective commitment and turnover intention variables are concluded as reliable because the Cronbach's Alpha score are $0.934,0.831,0.685,0.780$ and 0.794 , respectively which are more than 0.6.

\section{Analyses}

This research will use multiple regression analysis to test the influence of three independent variables toward the dependent variable (Gujarati, 2009). This regression will examine the relationship between burnout components (exhaustion, cynicism, and reduced professional efficacy as independent variable) toward affective commitment and turnover intention as dependent variables.

\section{Result and Discussion}

\section{Statistics Summary and Hypothesis Testing}

Table 1. Descriptive Statistics

\begin{tabular}{lcc}
\hline & Descriptive Statistics & \\
\hline Variable & Mean & Standard Deviation \\
\hline Exhaustion & 2.28 & 0.93 \\
Cynicism & 2.25 & 0.69 \\
Reduced Professional Efficacy & 2.13 & 0.54 \\
Affective Commitment & 3.50 & 0.63 \\
Turnover Intention & 2.38 & 0.85 \\
\hline
\end{tabular}

**. Correlation is significant at the 0.01 level (2-tailed)

Source: Processed Primary Data, 2018 
Based on the descriptive statistics Table 1, it was found that the mean value of affective commitment is 3.50. It indicates that the employee experiences high level of affective commitment to organization. For turnover intention variable has a mean value of 2.38 indicating employee has low intention to leave organization. Then, burnout tendencies which consist of exhaustion, cynicism and reduced professional efficacy have average mean value of $2.28,2.25,2.13$, respectively. It implies that the employees experience lower level of burnout which is indicated by lower level of exhaustion, cynicism and reduced professional efficacy.

In the case of standard deviation, it is used to see the spread of the data in the sample as well as how close the distance of individual data to the sample mean. Exhaustion variable has the highest standard deviation by 0.93 meanwhile cynicism and reduced professional efficacy are 0.69 and 0.54. For affective commitment and turnover intention, the standard deviation reaches 0.63 and 0.85 .

Table 2. Multiple Regression Analysis Result for Affective Commitment

\begin{tabular}{|c|c|c|c|c|}
\hline \multicolumn{5}{|c|}{ Multiple Regression Test Result } \\
\hline \multirow[t]{2}{*}{ Model } & $\begin{array}{l}\text { Standardized } \\
\text { Coefficients }\end{array}$ & \multirow[t]{2}{*}{$\mathrm{t}$} & \multirow[t]{2}{*}{ Sig. } & \multirow[t]{2}{*}{ Result } \\
\hline & Beta & & & \\
\hline (Constant) & & 22.463 & & \\
\hline Exhaustion & -0.062 & -0.501 & 0.617 & Not Significant \\
\hline Cynicism & -0.507 & -4.251 & 0.000 & Significant \\
\hline Reduced Professional Efficacy & -0.185 & -2.045 & 0.044 & Significant \\
\hline \multirow{2}{*}{\multicolumn{5}{|c|}{$\begin{array}{l}\text { Constant }=22.463 \\
R^{2}=.426, \text { Adjusted } R^{2}=.407\end{array}$}} \\
\hline & & & & \\
\hline \multicolumn{5}{|l|}{ F-Statistic $=22.291 ;$ Sig $=0,000$} \\
\hline \multicolumn{5}{|c|}{ Confidence level $=95 \%($ alpha $=0.05)$} \\
\hline \multicolumn{5}{|c|}{ Unstandardized Coefficients B, Constant: 5.096} \\
\hline
\end{tabular}

The result of multiple linear regression on Table 2 shows that the exhaustion has no significant effect on affective commitment with value of t-statistic of -0.501 , regression coefficient by -0.062 , and significance value of $t$ equal to 0.617 (with alpha equal to 5\%). Based on the result, it means that the higher levels of exhaustion experienced by employees will not predict lower levels of employees' affective commitment. Thus, hypothesis 1a is not supported.

The result of multiple linear regression on Table 2 shows that the cynicism has negative and significant effect on affective commitment with value of t-statistic of -4.251 , regression coefficient by -0.507 , and significance value of t equal to 0.000 (with alpha equal to 5\%). Based on the result, it means that the higher levels of cynicism experienced by employees will predict lower levels of employees' affective commitment. Thus, hypothesis $1 \mathrm{~b}$ is supported.

The result of multiple linear regression on Table 2 shows that the reduced professional efficacy has negative and significant effect on affective commitment with value of t-statistic of -2.045, regression coefficient by -0.185 , and significance value of t equal to 0.044 (with alpha equal to 5\%). Based on the result, it means that the higher levels of reduced professional efficacy experienced by employees will predict lower levels of employees' affective commitment. Thus, hypothesis 1c is supported.

The result of multiple linear regression on Table 3 shows that the exhaustion has positive and significant effect on turnover intention with value of t-statistic of 3.130, regression coefficient by 0.327 , and significance value of $t$ equal to 0.002 (with alpha equal to 5\%). Based on the result, it means that the higher levels of exhaustion experienced by employees will predict higher levels of employees' turnover intention. Thus, hypothesis $2 \mathrm{a}$ is supported.

The result of multiple linear regression on Table 3 shows that the reduced professional efficacy has positive and significant effect on turnover intention with value of t-statistic of 3.042, regression coefficient by 0.232 , and significance value of $t$ equal to 0.003 (with alpha equal to 5\%). Based on the 
result, it means that the higher levels of reduced professional efficacy experienced by employees will predict higher levels of employees' turnover intention. Thus, hypothesis $2 \mathrm{c}$ is supported.

Table 3 Multiple Regression Analysis Result for Turnover Intention

\begin{tabular}{|c|c|c|c|c|}
\hline \multicolumn{5}{|c|}{ Multiple Regression Test Result } \\
\hline \multirow{2}{*}{ Model } & Standardized Coefficients & \multirow{2}{*}{$\mathrm{t}$} & \multirow{2}{*}{ Sig. } & \multirow{2}{*}{ Result } \\
\hline & Beta & & & \\
\hline (Constant) & & -0.241 & & \\
\hline Exhaustion & 0.327 & 3.130 & 0.002 & Significant \\
\hline Cynicism & 0.353 & 3.516 & 0.001 & Significant \\
\hline Reduced Professional Efficacy & 0.232 & 3.042 & 0.003 & Significant \\
\hline \\
\hline \multicolumn{5}{|l|}{$\mathrm{R}^{2}=0.592$, Adjusted $\mathrm{R}^{2}=0.579$} \\
\hline \multicolumn{5}{|l|}{ F-Statistic $=43.563 ; \mathrm{Sig}=0,000$} \\
\hline \multicolumn{5}{|l|}{ Confidence level $=95 \%($ alpha $=0.05)$} \\
\hline Unstandardized Coefficients B, Constant & -0.063 & & & \\
\hline
\end{tabular}

The result of multiple linear regression on Table 3 shows that the cynicism has positive and significant effect on turnover intention with value of t-statistic of 3.516, regression coefficient by 0.353 , and significance value of t equal to 0.001 (with alpha equal to 5\%). Based on the result, it means that the higher levels of cynicism experienced by employees will predict higher levels of employees' turnover intention. Thus, hypothesis $2 \mathrm{~b}$ is supported.

It was also found that the F-statistics for affective commitment and turnover intention variables are 22.291 and 43.563 with significance of 0.000 . It is known that the F-table value using the $95 \%$ confidence level is 2.14 . The model is proved to be significant if F-statistics is greater than the F-table. The result shows that the F-statistics > F-table (2.14). Thus, it can be concluded that three independent variables of exhaustion, cynicism, reduced professional efficacy simultaneously and thoroughly have a significant and negative effect on the dependent variable of affective commitment and turnover intention.

The adjusted $R$ square for affective commitment and turnover intention variable is 0.407 and 0.579 . The value indicates that the ability of exhaustion, cynicism and reduced professional efficacy variables in explaining affective commitment and turnover intention variable is $40.7 \%$ and $57.9 \%$, respectively.

\section{Discussion}

Based on the multiple regression test, it was obtained the result that five from six hypotheses are supported. For first hypothesis (H1), cynicism and reduced professional efficacy significantly and negatively influence affective commitment. Meanwhile, exhaustion was found to be insignificant on affective commitment. For second hypothesis (H2), exhaustion, cynicism and reduced professional efficacy have significant and positive effect on turnover intention.

For exhaustion variable, it focuses on measuring the work fatigue mentally and physically experienced by employees resulted from their day-to-day work. This research proved that exhaustion has no significant effect toward affective commitment. Evidently, this finding is in line with previous research by Jung \& Kim (2012), Fogarty and Kalbers (2015) and Cho et al. (2017). It implies that although employees have low level of exhaustion, it would not influence their level of affective commitment toward the organization. The accumulated tired activities from employees' work force them to exert all of their energy which creates severe fatigues. However, employees perceive that the lack of energy sources is derived from their individual work not from their organization. Thus, the lack of association between exhaustion and affective commitment is caused by employees who blame the job itself rather than the organization that provides them that job. 
Furthermore, the researcher tried to test the effect of three burnout tendencies as one construct of burnout towards the affective commitment variable. The result stated that burnout as one construct has significant and negative effect on affective commitment. Meanwhile, if the burnout tendencies are tested separately as three variables, exhaustion variable has no significant effect on affective commitment. The reason for this phenomenon is probably because the characteristics of the job received by the individuals indeed force them to work optimally and maximally which exert their fatigue. So, the feeling of exhaustion experienced by the employees is perceived to be normal in order to perform the job given to the employees. Then, it only affects whether they like or dislike their organization not their emotional attachment to involve in organizational activities.

Cynicism variable is the variable which measures the degree of their feeling of negative attitudes toward their daily work in general. In this research, cynicism variable has significant and negative effect toward affective commitment. It implies that when employees experience high level of cynicism, it declines the level of affective commitment experienced by the employees. This finding corresponds with the previous research from Buys and Rothmann (2010), Jung and Kim (2012) and Fogarty and Kalbers (2015). The sense of feeling that their jobs are not suitable and fit with their interest induces their negative evaluation of their duties and responsibilities. Then, it persuades them to exhibit negative behaviour in the organization to involve in organizational activities and do not want to sacrifice their personal efforts for organizational importance. On the other word, the higher level of negative attitudes perceived by the employees in regards with their relationship toward their job, the lower level of their emotional attachment, identification and involvement with their organization.

In the case of reduced professional efficacy, it is the variable which concentrates on measuring the level of employees' expectations of their work contribution to organization outcomes. Based on the results, reduced professional efficacy has significant and negative effect on affective commitment. It shows that the high level of reduced professional efficacy perceived by employees will decrease the level of employees' affective commitment. This finding supports the previous research by Fogarty and Kalbers (2015) and Jung and Kim (2012). Employees' confident is one's ability contributing to the successful execution of the job well done. The employees who no longer feel that they contribute to the work environment have diminished affection for their job and organization. The feelings of employees who feel inadequate to complete the work in accordance with the desired results will be translated into the idleness on their daily task. Since the employees feel that their job does not donate worth wile contributions to organization goals, it drives employees to impede their effort on organizational behalf. On the other word, employees are more likely to provide minimum attempt through their job for their organization if they feel that they have lack of competences to perform the job well and perceived that their job does not give significant contribution to organization's outcomes.

The impact of exhaustion toward turnover intention was proved to be positively significant. This finding is consistent with previous work by Huang et al. (2003), Jung and Kim (2012) and Chen and Yu (2014). Higher level of exhaustion will predict higher level of intention to leave an organization. Employees with recurring tension and frustration derived from their work may feel emotionally drained, then, they may be reluctant to work another day. The continuous of those working conditions will attract them to search for new jobs outside the organization in order to release their fatigue by looking for new environment. Nevertheless, supporting function employees in PT. $\mathrm{XYZ}$ have low level of exhaustion which indicates low level of experienced burnout, consequently, it generates low intention to leave organization.

Evidently, this research found significant and positive effect between cynicism and turnover intention. This finding support previous work by Huang (2003), Jung and Kim (2012), and Jung et al. (2012). Cynicism, as one of burnout symptoms, depicts distant attitudes from the job which caused by a greater sense of helplessness arising from complicated, repetitive tasks, and rigid hierarchies will contribute to the rise of turnover intent. The uncomfortable feeling which might be originated from the incompatibility between employees' expectations of the job and its actual job trigger the distant 
attitudes toward their job. Those attitudes gradually turn into employees' destructive behaviours which produces negative job outcomes of the increasing desire to leave the organization to look for new job. However, in this case, since the level of cynicism experienced by employees is low, so does the negative attitudes of the employees are low. Because of that, employees do not generate distractive behaviour in the organization. Thus, it is implied that most of employees have less intention to leave the organization.

Moreover, the relationship between reduced professional efficacy and turnover intention also produce similar finding with the work of Jung \& Kim (2012). It was found that reduced professional efficacy positively influences employees' turnover intention. As previously proved by Jung et al. (2012) and Reinardy (2011), lower sense of perceived achievement felt by the employees will generate higher turnover intention on the workplace. The sense of not being able to do certain jobs provides the chance for employees to dubious their ability, then, it will induce the gloom of working in the organization. The more employees do not perform well on their duties, the more organization questions the competences possessed by them and their contribution on organizational goals. Then, it causes employees to leave the organization looking for another suitable position.

\section{Conclusion}

Based on the results analysis, the research's conclusion could be explained, as follows: (1) Exhaustion has no effect on affective commitment. The level of exhaustion experienced by employees does not influence the level of employees' affective commitment; (2) Cynicism has negative and significant effect on affective commitment. The higher level of negative attitudes toward their job perceived by employees, the higher level of their emotional attachment with their organization; (3) Reduced professional efficacy has negative and significant effect on affective commitment. The employees' contribution for organization and ability to complete their job affect their involvement to remain in the organization; (4) Exhaustion has positive and significant effect on turnover intention. The higher level of tension and frustration felt by employees will produce higher level of intention to leave the organization; (5) Cynicism has positive and significant effect on turnover intention. The greater negative attitudes perceived by employees toward their job, the greater employees' intention to leave the organization; (6) Reduced professional efficacy has positive and significant effect on turnover intention. Thus, the level of achievement felt by employees influences the desires of employees to leave the organization.

\section{Limitation and Suggestion}

These are several limitations which are accompanied by the suggestions for further research, as follows: (1) The results of this study cannot be generalized to other oil and gas or stated owned companies as a whole, because this study only refers to one oil and gas stated owned company. In order to generalize the results of the study, this research suggests to use samples from more than one company which engaged in different field areas; (2) The samples used in this study are not equally distributed among departments within enabler function. It is caused by the company which already has full of agenda in their daily working activities, thus, employees do not have plenty of free time to participate in the study. Future research could arrange the data gathering schedule in advance in order to give more time to company in preparing and informing their employees regarding the researches' needs; (3) The lack of attention from the company at the time of data collection leads to the limited involvement of company in this study. It is feared that it may affect the seriousness and honesty of employees to participate in filling out the questionnaires given by the researcher. To anticipate this, further research should have close and intimate session with the respondents accompanied by the management so that employees can know the importance of the topic under study and have particular time to fill out the questionnaire; (4) The variables studied in this study only include affective commitment and turnover intention variables as burnout tendencies' consequences of exhaustion, 
cynicism and reduced professional efficacy variables. Future research could add and examine other factors which may arise due to the occurrence of burnout tendencies such as job satisfaction, employee performance, and employee engagement.

\section{References}

Al-Turki, H. A., Al-Turki, R. A., Al-Dardas, H. A., Al-Gazal, M. R., Al-Maghrabi, G. H., Al-Enizi, N. H., \& Ghareeb, B. A. (2010). Burnout syndrome among multinational nurses working in Saudi Arabia. Annals of African Medicine, 9(4).

Allen, N. J., \& Meyer, J. P. (1990). The measurement and antecedents of affective, continuance and normative commitment to the organization. Journal of occupational and organizational psychology, 63(1), 1-18.

Allen, N. J., \& Meyer, J. P. (1996). Affective, continuance, and normative commitment to the organization: An examination of construct validity. Journal of vocational behavior, 49(3), 252276.

American Psychological Association. (2017). Change at Work Linked to Employee Stress, Distrust and Intent to Quit, New Survey Finds. Retrieved from http://www.apa.org/news/press/releases/2017/05/employee-stress.aspx

Armstrong, D. J., Brooks, N. G., \& Riemenschneider, C. K. (2015). Exhaustion from information system career experience: implications for turn-away intention. Applied Psychology, 86(3), 499-512.

Atmaja, Allan Maulana. 2018. (2018, January 8). Personal interview with Komar, Koko \& Raudha, Esha.

Brown, S. P., \& Peterson, R. A. (1993). Antecedents and consequences of salesperson job satisfaction: Meta-analysis and assessment of causal effects. Journal of marketing research, 30(1), 63.

Buys, C., \& Rothmann, S. (2010). Burnout and engagement of reformed church ministers. SA journal of industrial psychology, 36(1), 1-11.

Cannon, N. H., \& Herda, D. N. (2016). Auditors' Organizational Commitment, Burnout, and Turnover Intention: A Replication. Behavioral Research in Accounting, 28(2), 69-74.

Carmeli, A., \& Weisberg, J. (2006). Exploring turnover intentions among three professional groups of employees. Human Resource Development International, 9(2), 191-206.

Carod-Artal, F. J., \& Vázquez-Cabrera, C. (2013). Burnout syndrome in an international setting. In Burnout for experts (pp. 15-35). Springer, Boston, MA.

Chen, C. F., \& Yu, T. (2014). Effects of positive vs negative forces on the burnout-commitmentturnover relationship. Journal of Service Management, 25(3), 388-410.

Cho, S., Johanson, M. M., \& Guchait, P. (2009). Employees intent to leave: A comparison of determinants of intent to leave versus intent to stay. International Journal of Hospitality Management, 28(3), 374-381.

Cho, Y. N., Rutherford, B. N., Friend, S. B., Hamwi, G. A., \& Park, J. (2017). The role of emotions on frontline employee turnover intentions. Journal of Marketing Theory and Practice, 25(1), 5768.

Chong, V. K., \& Monroe, G. S. (2015). The impact of the antecedents and consequences of job burnout on junior accountants' turnover intentions: a structural equation modelling approach. Accounting \& Finance, 55(1), 105-132. 
Cordes, C. L., \& Dougherty, T. W. (1993). A review and an integration of research on job burnout. Academy of management review, 18(4), 621-656.

Du Plooy, J., \& Roodt, G. (2010). Work engagement, burnout and related constructs as predictors of turnover intentions. SA Journal of Industrial Psychology, 36(1), 13.

Enzmann, D., Schaufeli, W. B., Janssen, P., \& Rozeman, A. (1998). Dimensionality and validity of the Burnout Measure. Journal of occupational and organizational psychology, 71(4), 331-351.

Farradinna, S., \& Halim, F. W. (2016). The Consequences of Work-family Conflict, Burnout and Organizational Commitment among Women in Indonesia. Procedia-Social and Behavioral Sciences, 219, 241-247.

Fogarty, T. J., \& Kalbers, L. P. (2015). Internal auditor burnout: An examination of behavioral consequences. In Advances in Accounting Behavioral Research (pp. 51-86). Emerald Group Publishing Limited.

Freudenberger, H. J. (1974). Staff burn-out. Journal of social issues, 30(1), 159-165.

Freudenberger, H. J. (1975). The staff burn-out syndrome in alternative institutions. Psychotherapy: Theory, Research \& Practice, 12(1), 73.

Gouthro, D. (2017). The Employee Burnout Crisis: Study Reveals Big Workplace Challenge in 2017. Kronos. Retrieved 8 December 2017, from https://www.kronos.com/aboutus/newsroom/employee-burnout-crisis-study-reveals-big-workplace-challenge-2017

Grandey, A. A. (2000). Emotional regulation in the workplace: A new way to conceptualize emotional labor. Journal of occupational health psychology, 5(1), 95..

Greenglass, E. R., \& Burke, R. J. (2002). Hospital restructuring and burnout. Journal of health and human services administration, 89-114.

Gujarati, D., \& Porter, D. (2009). Basic econometrics. New York: McGraw-Hill Irwin.

Hedges, K. (2017). Forbes Welcome. Forbes.com. Retrieved 7 December 2017, from https://www.forbes.com/sites/work-in-progress/2015/07/08/competition-at-work-positive-orpositively-awful/\#4bb343f2da84

Herda, D. N., \& Lavelle, J. J. (2012). The auditor-audit firm relationship and its effect on burnout and turnover intention. Accounting Horizons, 26(4), 707-723.

Houtman, I., Jettinghof, K., Cedillo, L., \& World Health Organization. (2007). Raising awareness of stress at work in developing countries: a modern hazard in a traditional working environment: advice to employers and worker representatives.

Huang, I. C., Chuang, C. H. J., \& Lin, H. C. (2003). The Role of Burnout in the Relationship between Perceptions off Organizational Politics and Turnover Intentions. Public Personnel Management, 32(4), 519-531.

Iwanicki, E. F., \& Schwab, R. L. (1981). A cross validation study of the Maslach Burnout Inventory. Educational and psychological measurement, 41(4), 1167-1174.

Jung, H. S., Yoon, H. H., \& Kim, Y. J. (2012). Effects of culinary employees' role stress on burnout and turnover intention in hotel industry: moderating effects on employees' tenure. The Service Industries Journal, 32(13), 2145-2165.

Jung, J., \& Kim, Y. (2012). Causes of newspaper firm employee burnout in Korea and its impact on organizational commitment and turnover intention. The International Journal of Human Resource Management, 23(17), 3636-3651. 
Kang, B., Twigg, N. W., \& Hertzman, J. (2010). An examination of social support and social identity factors and their relationship to certified chefs' burnout. International Journal of Hospitality Management, 29(1), 168-176.

Kim, J. (2015). What Increases Public Employees' Turnover Intention?.Public Personnel Management, 44(4), 496-519.

Leiter, M. P., \& Schaufeli, W. B. (1996). Consistency of the burnout construct across occupations. Anxiety, stress, and coping, 9(3), 229-243.

Lim, J., Bogossian, F., \& Ahern, K. (2010). Stress and coping in Singaporean nurses: a literature review. Nursing \& Health Sciences, 12(2), 251-258.

Lynne, M. (2017). Impacts of Organizational Behavior in Business. Chron. Retrieved 3 December 2017, from http://smallbusiness.chron.com/impacts-organizational-behavior-business48407.html

Maslach, C., \& Jackson, S. E. (1981). The measurement of experienced burnout. Journal of organizational behavior, 2(2), 99-113.

Maslach, C., Schaufeli, W. B., \& Leiter, M. P. (2001). Job burnout. Annual review of psychology, 52(1), 397-422.

Memari, N., Mahdieh, O., \& Marnani, A. B. (2013). The impact of Organizational Commitment on Employees Job Performance." A study of Meli bank. Interdisciplinary journal of contemporary research in business, 5(5), 164-171.

Meyer, J. P., \& Allen, N. J. (1987). A longitudinal analysis of the early development and consequences of organizational commitment. Canadian Journal of Behavioural Science/Revue canadienne des sciences du comportement, 19(2), 199.

Meyer, J. P., \& Allen, N. J. (1991). A three-component conceptualization of organizational commitment. Human Resource Management Review, 1, 61-89.

Morgan, G. (2017). The 5 Things That Are Causing Employees To Burn Out. Fast Company. Retrieved 6 December 2017, from https://www.fastcompany.com/3067827/the-5-things-that-arecausing-employees-to-burn-out

Mowday, R. T., Steers, R. M., \& Porter, L. W. (1979). The measurement of organizational commitment. Journal of vocational behavior, 14(2), 224-247.

Nagar, K. (2012). Organizational commitment and job satisfaction among teachers during times of burnout. Vikalpa, 37(2), 43-60.

O'Reilly, C. A., Chatman, J., \& Caldwell, D. F. (1991). People and organizational culture: A profile comparison approach to assessing person-organization fit. Academy of management journal, 34(3), 487-516.

Reinardy, S. (2011). Newspaper journalism in crisis: Burnout on the rise, eroding young journalists' career commitment. Journalism, 12(1), 33-50.

Roelofs, J., Verbraak, M., Keijsers, G. P., De Bruin, M. B., \& Schmidt, A. J. (2005). Psychometric properties of a Dutch version of the Maslach Burnout Inventory General Survey (MBI-DV) in individuals with and without clinical burnout. Stress and Health, 21(1), 17-25.

Schawbel, D. (2017). What Employers Will Worry About in 2017. Fortune. Retrieved 7 December 2017, from http://fortune.com/2016/12/28/employers-2017-employee-retentionunemployment/ 
Schaufeli, W. B., Leiter, M. P., \& Maslach, C. (2009). Burnout: 35 years of research and practice. Career development international, 14(3), 204-220.

Sekaran, U., \& Bougie, R. (2016). Research methods for business: A skill building approach. John Wiley \& Sons.

Shepherd, C. D., Marchisio, G., Morrish, S. C., Deacon, J. H., \& Miles, M. P. (2010). Entrepreneurial burnout: Exploring antecedents, dimensions and outcomes. Journal of research in marketing and entrepreneurship, 12(1), 71-79.

Solinger, O. N., Van Olffen, W., \& Roe, R. A. (2008). Beyond the three-component model of organizational commitment. Journal of applied psychology, 93(1), 70.

Steel, R. P. (2002). Turnover theory at the empirical interface: Problems of fit and function. Academy of Management Review, 27(3), 346-360.

Steinhage, A., Cable, D., \& Wardley, D. (2017). The Pros and Cons of Competition Among Employees. Harvard Business Review. Retrieved 5 December 2017, from https://hbr.org/2017/03/the-pros-and-cons-of-competition-among-employees

Tan, D. S., \& Akhtar, S. (1998). Organizational commitment and experienced burnout: An exploratory study from a Chinese cultural perspective. The International Journal of Organizational Analysis, 6(4), 310-333.

Tourigny, L., Baba, V. V., Han, J., \& Wang, X. (2013). Emotional exhaustion and job performance: the mediating role of organizational commitment. The International Journal of Human Resource Management, 24(3), 514-532.

Utami, I., \& Nahartyo, E. (2013). The effect of Type A personality on auditor burnout: Evidence from Indonesia.

Valcour, M. (2017). 4 Steps to Beating Burnout. Harvard Business Review. Retrieved 31 January 2018, from https://hbr.org/2016/11/beating-burnout

Werang, B. R., Asmaningrum, H. P., \& Irianto, O. (2015). Relationship Between Teachers' Job Burnout, Teachers' Organizational Commitment, and Teachers Job Performance at State Elementary Schools in Boven Digoel Regency, Papua, Indonesia. International Journal of Science and Research (IJSR), 4(2), 826 - 830 